\title{
APROXIMACIONES AL ITINERARIO DE UN GÉNERO TEATRAL EN EL SIGLO XVII, A PROPÓSITO DE LAS LOAS PALACIEGAS DE CALDERÓN DE LA BARCA
}

\author{
Judith Farré \\ CSIC, Madrid \\ [Anuario calderoniano (ISSN: 1888-8046), 2, 2009, pp. 143-179]
}

Todo apunta a que la primera aparición de la loa en el teatro español data de 1513, cuando Juan del Encina se sirvió de este tipo de piezas preliminares para encabezar la representación de la Égloga de Plácida y Victoriano ${ }^{1}$. Como ya pusiera de manifiesto Flecniakoska en

${ }^{1}$ Kurt Spang (1994, p. 11) coincide con Miguel Zugasti: «La loa, que ya existió en los teatros sánscrito, griego, latino, franco-medieval, se manifiesta por primera vez en 1513, precediendo a la Égloga de Plácida y Victoriano de Juan del Encina» (Zugasti, 2002, p. 198). Por su parte, Emilio Cotarelo propone como primeras manifestaciones del género las que preceden a autos sacramentales: «Empleose desde luego, quizá por mayor respeto, en los autos sacramentales más antiguos que conocemos. La primera obra del códice de la Biblioteca Nacional que contiene los del siglo XVI (El sacrificio de Abraham), lleva una Loa al Sacramento, o lo que es igual, Alabanza al Sacramento. No tardó en pasar con el mismo sentido al teatro profano, o al menos con aplicación a cosas profanas. En la Farsa de Tamar (antes de 1550), compuesta por Diego Sánchez de Badajoz, interrúmpese la acción hacia el final para colocar unos versos, diciendo: "Y tras esto lo siguiente, que es en loa del Conde de Feria"» (Cotarelo, 1911, vol. 1, 
su monografía sobre el género (1975), «aunque es la loa un género menor, nos parece muy útil conocer bien sus mecanismos no sólo con la intención de tener una visión de conjunto del espectáculo global, [...], sino también para conocer mejor las relaciones que podían existir entre los representantes y el público» ${ }^{2}$. Si bien cabe destacar que el propósito de Flecniakoska es el estudio de la loa desde «los orígenes conocidos del teatro español hasta fines de la primera mitad del siglo $\mathrm{XVII}^{3}{ }^{3}$, es decir, se centra exclusivamente en su forma de monólogo recitado ${ }^{4}$. También Francisco Rico (1979) se ocupó de trazar el itinerario de esta primera fase del género, en su vertiente de monólogo, cuando la loa «brota y crece al amparo de la vieja tradición panegírica, abreva en sus varias corrientes, en ellas sobre todo descubre fórmulas, sugerencias o dechados inmediatos $»^{5}$.

Los primeros estadios de evolución del género en el siglo XVI hasta mediados del XVII se determinan tanto por su dependencia argumental con la comedia que se iba a representar a continuación, como por la coincidencia de funciones con «los géneros retóricos y literarios de índole epidíctica o panegírica, ante todo la laudatio, el encomio y el epitalamio» ${ }^{6}$. Esta dependencia argumental respecto a la pieza larga que seguirá es quizá una de las funciones más cambiantes, y, a la larga, será el factor definitivo a la hora de trazar la evolución del género. Es lógico pensar que si la función introductoria de la loa determina predisponer al público frente al espectáculo teatral que está por empezar,

p. VI). Stefano Arata y Fausta Antonucci se decantan por la loa de la Farsa llamada Danza de la Muerte de Juan de Pedraza como primer testimonio de su empleo en el teatro español y precisan que «el término vuelve a aparecer en el Códice de autos viejos (1555-1570) para indicar los versos introductorios a numerosos autos de la colección. Si la cronología fragmentaria de que disponemos no nos engaña, es con la tragedia Alejandra (hacia 1581) de Lupercio Leonordo de Argensola cuando la palabra empieza su afortunado recorrido en el teatro profano, procedente directamente de los autos religiosos» (Antonucci-Arata, 1995, p. 10).

${ }^{2}$ Flecniakoska, 1975, p. 10.

${ }^{3}$ Flecniakoska, 1975, p. 11.

${ }^{4}$ Las loas de la Jocoseria de Quiñones de Benavente (1645) son para Flecniakoska el punto de inflexión para considerar la morfología del género, ya que a partir de este momento considera que "la loa viene a ser como un entremés, con varias figuras, presentado en su propio decorado» (Flecniakoska, 1975, p. 11).

5 Rico, 1979, p. 615.

6 Spang, 1994, p. 10. 
a medida en que éste se convierta en un producto de consumo habitual, lo que prevalecerá es la necesidad de sorprender y captar la atención del auditorio. El reclamo de cara al público que impone ser la pieza de inicio permitirá observar cómo progresivamente la introducción a la comedia podrá combinarse con el resumen de su argumento o la presentación de sus protagonistas, hasta la elección de «sucesos fabulosos, / ficciones, burlas, engaños, / alabanzas, vituperios, / enigmas y cuentos varios» ${ }^{7}$ o de argumentos procedentes de la consideración del mismo oficio teatral. De ahí que lo esencial para considerar la evolución del género sea, como veremos, su dependencia respecto al espectáculo y, bajo la tradición de la fórmula panegírica, lo que se impondrá es su versatilidad en función de las circunstancias de representación.

En esta fase inicial del género coexisten diferentes formas de nombrarlo, tales como loa, introito, prólogo, preludio, argumento..., aunque dicha variedad resulta significativa de los dos aspectos básicos de esta tipología genérica inicial, es decir, la síntesis argumental de la pieza larga a la que precedía la loa, así como el elogio, la mayoría de las veces dedicado al público que acudía a los corrales de comedias "para ver representar» ${ }^{8}$. Tras esta indeterminación inicial, sintomática de la misma incertidumbre a la hora de definir sus funciones teatrales como género dentro del continuum dramático de la representación, el término que acabaría imponiéndose con el tiempo es el de lo $a^{9}$, lo cual resulta de nuevo indicativo, tanto del progresivo deslinde argumental entre la loa y la comedia, como de la importancia que desempeña el encomio en este tipo de piezas de teatro breve.

Y bajo esta última acepción se redacta la entrada de loa en el Diccionario de Autoridades de 1734: «Llámase así porque su asunto es siempre en alabanza de aquel a quien se dedican». La selección léxica que opera en este caso, no solo deja perfectamente establecida la tradición retórica que relaciona el género teatral de la loa con los propios de la laudatio clásica, sino que también nos proporciona uno de

7 Rico, 1979, p. 612.

${ }^{8}$ Loa de Lope de Vega (8) en Antonucci-Arata, 1995, p. 83.

${ }^{9}$ En este sentido, Cotarelo es explícito al iniciar su prólogo sobre loas: «No cabe duda que el sentido recto de la palabra loa (alabanza) es lo que determinó su aplicación al teatro, para designar los preludios o introducciones de las obras dramáticas» (Cotarelo, 1911, vol. 1, p. VI). 
los aspectos fundamentales sobre los que trazar el itinerario del género, ya que el hecho de que prevalezca la noción del elogio al destinatario supone que el eje de referencia ya no es la ficción dramática de la comedia que sigue a la loa, sino las circunstancias de representación sobre las que se asienta toda la puesta en escena en la que se inserta. De ahí que pueda considerarse una propuesta para su tipología genérica que contemple diferentes subgéneros de acuerdo a los distintos espacios y circunstancias de representación.

En los estadios iniciales de configuración del género durante todo el siglo XVI puede constatarse cómo la loa carece de una consideración espectacular, es recitada por un solo actor frente al telón y su función primordial es la de establecerse, dentro del ritual de iniciación para preparar al público en la ficción dramática, como una especie de bisagra entre el tablado y la platea. En un primer momento, asentada ya la denominación de loa, esta forma preliminar consistía, básicamente, en una alabanza al público, en presentar algunos detalles de la obra y resumir su argumento, para pasar a cerrar con una petición de silencio hacia el ilustre senado ${ }^{10}$.

Una segunda fase de evolución en este recorrido inicial del género durante el siglo XVI puede apreciarse a partir de $1580^{11}$, cuando los corrales de comedias son ya lugares fijos destinados a albergar las representaciones teatrales, y en donde la profesionalización de los diversos aspectos que integran el entramado dramático por estos años, los convierten en sedes estables de un pujante circuito comercial, regido por

10 Tal y como puso de manifiesto Flecniakoska, «cautivar la benevolencia significa proteger a la compañía de la posible furia de los mosqueteros, los chillidos de la cazuela, acompañados por música de llaves, los lanzamientos de fruta podrida o de edificio. Para los representantes es indispensable también la benevolencia del público en el plano de la comprensión y el perdón de los imprescindibles errores que pueden deslizarse en el texto y en el juego escénico» (Flecniakoska, 1975, p. 64).Ver también Antonucci-Arata, 1995, p. 10.

${ }^{11}$ Como afirma John J. Allen, «Para 1574, cuando se construyó el Corral de las Atarazanas en Sevilla, había comenzado el extraordinario florecimiento de los corrales de comedias; a comienzos del siglo XVII había corrales por toda la Península, concentrándose esta abundante actividad teatral sobre todo en Sevilla, Valencia y Madrid. El desarrollo posterior del teatro en España parte de este cambio fundamental, ya que con el control del acceso al espectáculo la actividad teatral pasa a ser negocio, lo que posibilita la formación de compañías de actores y la profesionalización de la empresa teatral» (Allen, 2003, p. 629). 
las leyes de la oferta y la demanda. En este sentido resultan muy sugerentes los comentarios de Ruano de la Haza, ya que la construcción de este tipo de edificios destinados exclusiva y permanentemente al espectáculo teatral, suponían, además, que "el heterogéneo público no sólo veía y oía la representación sino que también contemplaba con admiración el mismo edificio»" ${ }^{12}$, lo cual resulta significativo de las implicaciones de esta nueva experiencia teatral para el público. Sus conclusiones acerca de la puesta en escena en los teatros comerciales del siglo XVII podrían extenderse a la hora de considerar la evolución de la morfología genérica de la loa, puesto que del mismo modo que los decorados tenían una función más bien icónica, «en el sentido que establecían una relación analógica y convencional con el lugar que querían representar» ${ }^{13}$, y sinecdótica, la loa, a partir de la segunda mitad del siglo XVII y en el marco de este nuevo consumo teatral, podría considerarse como una fórmula eficaz para poner de manifiesto, también visual y sinecdóticamente, las implicaciones que supone la profesionalización del espectáculo dramático y su consideración como negocio. En esta fase podríamos hablar, tal y como ya precisaron Antonucci y Arata, de una función reivindicativa de la loa, puesto que:

la nueva poética, basada en una producción casi industrial, necesitaba una prótasis dramática más económica y ecléctica. Un tipo de prólogo que se pudiese utilizar para diferentes comedias y en diversas situaciones, aportando en todo caso mínimos retoques. No se trataba solo de una necesidad de ahorro de trabajo impuesta por la nueva industria teatral. La cuestión es que los autores ya no necesitaban presentar frente al auditorio la pieza en sí y tampoco resumir previamente la intriga. En el sistema de la comedia nueva, una vez aprendido el paradigma, cualquier espectador podía seguir sin dificultad las infinitas variantes que cada pieza aportaba. Lo que había que arrancar al público, sobre todo, en los primeros años, era más bien la aceptación de la nueva fórmula teatral en su conjunto e instruirle sobre cómo había que recibir el nuevo código dramático ${ }^{14}$.

12 Ruano de la Haza, 2000, p. 36.

13 Ruano de la Haza, 2000, pp. 327-328.

14 Antonucci y Arata, 1995, p. 12. 
Y es precisamente esta dependencia espectacular de la loa la que de forma inevitable la consagra como un género dramático ligado de manera muy estrecha a la evolución del arte nuevo de hacer comedias, el aspecto que más ha llamado la atención de críticos como Miguel Zugasti (1995, 2002) y Evangelina Rodríguez (1998), entre otros. Mientras el primero propone considerar la loa como «un género multiforme, permeable a las influencias extragenéricas, que refleja con gran nitidez la constante evolución del teatro español a lo largo del Siglo de Oro» ${ }^{15}$, Rodríguez Cuadros vincula la loa del XvII al proceso de estudio del actor barroco y precisa que si bien «la loa, sobre la cual la idea más generalizada es que se trata simplemente de un procedimiento retórico para predisponer al público e iniciar el espectáculo [...] lo cierto es que se trata de un lugar propicio donde se reflexiona verbalmente (retóricamente) pero también desde la acción (desde el cuerpo del actor) sobre el mito teatral» ${ }^{16}$. De ahí, creo, debe partir la consideración de su morfología durante el Barroco, puesto que precisamente la ausencia de un conflicto dramático definido en términos de acción propicia, forzosamente, que su asunto gire en torno al mismo espectáculo teatral.

A la hora de considerar la reconstrucción histórica del género durante la segunda mitad del siglo XVII, otro de los referentes fundamentales es el pionero estudio llevado a cabo por Emilio Cotarelo, quien en su Colección de 1911 propone la primera clasificación genérica, de la que necesariamente parten todas las ordenaciones y estudios posteriores. Cotarelo distingue entre esta nueva clase de loas, cuyos rasgos distintivos identifica a partir de Agustín de Rojas, cinco tipos: loas sacramentales; loas al nacimiento de Cristo, a Nuestra Señora y a los santos; loas de fiestas reales; loas para casas particulares y loas de

15 Zugasti, 2002, p. 198.

16 Rodríguez Cuadros, 1998, p. 559. Cabe señalar también que, en el estudio de la producción breve de Calderón que realizara junto a Antonio Tordera (1983), al hablar de las loas calderonianas, precisaran que no puede olvidarse cómo estos textos «muestran ciertamente la huella de la «circunstancia» de la representación (palaciega, de corral, particular o doméstica) [y] son un documento entrañable para el conocimiento de la precaria vida de los cómicos, una parcela del espectáculo en la que probablemente en más de una ocasión se ofrecían el autohomenaje que casi siempre les negó una sociedad que dejaba su condición de público a las puertas de los corrales, una vez concluida la representación» (Rodríguez-Tordera, 1983, p. 32). 
presentación de compañías ${ }^{17}$. Cotarelo toma como criterio la reconstrucción histórica del género, por lo que sus fuentes son siempre testimonios impresos, sin tener en cuenta los manuscritos, cuya datación podría resultar problemática.

Posteriormente, Stefano Arata y Fausta Antonucci editaron una colección de veintinueve loas manuscritas, atribuidas a Lope de Vega, Bautista de Vivar, Pedro Díaz y otros dramaturgos del Xvi ${ }^{18}$, que permanecían inéditas en la Biblioteca de Palacio y la Nacional de Madrid. La edición de este corpus, cuyo período de redacción puede datarse entre 1585 y $1595^{19}$, resulta una decisiva aportación al itinerario del género, no solo por lo que respecta a la recuperación de los textos en sí, sino también por el hecho de que por primera vez se consideran fuentes manuscritas y, además, se establece una nueva cronología en la evolución de la loa, ya que el cambio de formulación genérica podría fijarse entonces con anterioridad a Agustín de Rojas. Ello permite ligar estrechamente su evolución genérica a la profesionalización de los diversos aspectos que integran el entramado del teatro áureo, tal y como apuntábamos en las primeras líneas de este ensayo. Así lo asentaban Arata y Antonucci en la introducción a la edición al decir que

Sea cual sea el origen del término y su prehistoria, lo único cierto es que, después de 1580, la loa va adquiriendo en muy pocos años una fisonomía distinta de las formas anteriores. Esta transformación coincide con el triunfo de los teatros estables y bien se puede afirmar que la historia de la loa va a ser, de ahora en adelante, la historia del nuevo teatro y de la nueva poética teatral ${ }^{20}$.

17 Cotarelo, 1911, vol. 1, pp. XIV-LIII.

18 Antonucci-Arata, 1995, p. 23.

19 «Contrariamente a lo que se ha sugerido a veces, Agustín de Rojas no parece haber sido ningún innovador ni abrió nuevos horizontes en el arte dramático. Por un evidente error de perspectiva, el hecho de haber sido el primero en poner en letras de molde una colección de loas lo ha transformado a los ojos de muchos estudiosos en pionero del género. Las veintinueve loas que publicamos en este volumen, y que proceden de una valiosa colección teatral que ha quedado hasta ahora inédita, pertenecen todas a la reforma teatral de finales del XVI», Antonucci-Arata, 1995, pp. 15-16.

${ }^{20}$ Antonucci-Arata, 1995, p. 10. 
En otro de los escasos acercamientos orientados a establecer una delimitación teórica del género, a Kurt Spang (1994) se le debe una revisión de la propuesta de Cotarelo en la que plantea la necesidad de partir de una definición supragenérica de la loa. Spang propone una nueva clasificación subgenérica donde distingue entre la loa sacramental y religiosa; la loa palaciega; loas de presentación de compañías; loas de uso repetido y loas híbridas ${ }^{21}$.

Si partimos del hecho de que puede distinguirse una fase intermedia en la configuración del género, anterior a El viaje entretenido de Agustín de Rojas (1603), que se localizaría entre finales del siglo XVI y principios del XVII - lo que se desprende al considerar también fuentes manuscritas, como es el corpus de loas de 1585 a 1595 estudiado y editado por Antonucci y Arata en 1995-, podemos determinar que esas «loas de uso repetido» podrían corresponder a esa etapa en la que, ya con anterioridad al siglo XVII, la loa, como género inaugural de la representación, desempañaba una función reivindicativa, como reflejo del asentamiento de una nueva poética teatral y fruto de una creciente demanda en el circuito comercial instaurado por los corrales de comedias. Así esta «loa de uso repetido» podría corresponder a una fase previa, en la que resultaba necesaria «una prótasis dramática más económica y ecléctica» ${ }^{22}$, que, con mínimas variaciones, ilustrara al público en este nuevo horizonte de recepción dramática.

Asimismo, las «loas híbridas», otra de las variantes del género que distingue Kurt Spang, nos conducen a considerar un proceso de contacto característico del teatro breve y que, en el caso del teatro de los Siglos de Oro, protagoniza sobre todo el entremés, imponiéndose y difuminando las fronteras entre la mayoría de los géneros breves que se integran en la representación. La preponderancia del entremés dentro de los intermedios teatrales lo convierten en la pieza básica y, como ha puesto de manifiesto reiteradamente Huerta Calvo, es a la luz del modelo entremesil como van formalizándose el resto de las formas de teatro breve ${ }^{23}$. Todo ello nos confirma una tendencia general del teatro

21 Spang, 1994, pp. 9-10.

22 Antonucci-Arata, 1995, p. 12.

23 «Dentro de la fiesta teatral el entremés es la pieza básica, representada en principio entre el primero y segundo entreactos, pero pronto y bajo el modelo entremesil, fueron surgiendo otras modalidades especializadas en algunos rasgos temáticos o 
en esta época y que, en el caso de la loa, nos coloca frente a la loa dialogada o entremesada, característica del siglo XVII y en la que, según creo, podrían distinguirse, a partir de las variantes propuestas por Kurt Spang, las siguientes categorías: 1) loa cortesana $y$ de casas particulares ${ }^{24}$; 2) loa sacramental y religiosa y 3) loa de corral $y$ de presentación de com pañías $^{25}$. Estas tres formas tendrían que ver con las distintas circunstancias y espacios de representación característicos del teatro durante el siglo XVII, por lo que de este modo se confirmaría de nuevo la eventualidad que determina el género que, a partir de una tipología genérica única, adquiriría así esas tres modalizaciones, perfectamente definidas ya en la segunda mitad del siglo XVII.

A la luz de este sintético esbozo de los factores que determinan la evolución de la loa hasta la segunda mitad del siglo XVII, esta podría definirse, desde la misma naturaleza circunstancial que venimos apuntando, como el género dramático inaugural de la representación y el encargado de establecer la inicial connivencia con el público. La ausencia de un conflicto dramático definido en términos de acción convierte el motivo de la representación - ya sea una celebración religiosa determinada, el elogio a un destinatario de la monarquía o de la nobleza o bien la presentación de una compañía teatral ante el inicio de temporada - en el pretexto argumental y, en todos los casos, como bien indica el recto significado de «loa», las estrategias funda-

formales: el baile — con predominio del texto cantado sobre el recitado—, la jácara - un entremés sobre la vida airada de los jaques o valentones- y la mojiganga (traslación de la procesión carnavalesca, con su vistosidad y colorido, a los escenarios). Todas estas formas, junto con la loa — que abría el espectáculo- forman uno de los conjuntos de mayor riqueza de la historia del teatro no solo español sino europeo» (Huerta Calvo, 2002, p. 126).

${ }^{24}$ Aunque se trata del mismo modelo, debe considerarse una lógica diferencia en los medios escenográficos y en la intensidad de la hipérbole panegírica, que sitúan cualquier forma de teatro palaciego en los niveles más altos de ostentación.

25 Zugasti propone una distinción similar en lo esencial: «Asimismo, la loa es un género muy dependiente: bien de la obra larga a la que precede, o bien de las circunstancias concretas de representación: corral, palacio o casa particular, fiesta profana o fiesta religiosa (sacramental, hagiográfica...), cumpleaños, natalicio, boda... de algún poderoso, etc.» (Zugasti, 2002, p. 198). 
mentales del género apuntarían hacia el encomio de los destinatarios de la puesta en escena, es decir, la familia real o la nobleza, un misterio teológico, así como las virtudes actorales de una compañía dramática o la ciudad donde esta inicia su temporada teatral.

La estrategia encomiástica de la loa proporciona una especial forma de dialéctica entre realidad y ficción, en la que también se integra, bajo la ilusión dramática de una realidad envolvente, al auditorio presente en el espectáculo ${ }^{26}$. La loa se plantea así como una ficción dramática en la que las circunstancias que determinan la representación se convierten en el argumento espectacular que sintetiza en escena los principales valores que configuran la dramaturgia del elogio. La dicotomía entre realidad y ficción apela también a la simultaneidad del conflicto dramático para así envolver al auditorio en la participación conmemorativa de los valores panegíricos que se ostentan. La eficacia de dicho planteamiento reside en presentar la ilusión de contemporaneidad de la puesta en escena, por lo que al trazar ese argumento como un ir haciéndose a medida que va representándose, surgen de manera reiterada una serie de alusiones metateatrales acerca de la misma concepción y puesta en escena, lo cual, dicho sea de paso, incide de nuevo en el aspecto que más ha destacado la crítica reciente en sus análisis sobre la loa.

Así pues, a partir de las nociones de una realidad envolvente en la que se apela a la simultaneidad del conflicto dramático, cuyo argumento dramático gira en torno a la ostentación y el elogio de las circunstancias que propician la puesta en escena, puede plantearse una morfología genérica de la loa, según los distintos espacios y circunstancias de representación, y cuando ya adquiere, de acuerdo al mismo proceso de profesionalización y especialización del teatro barroco, plena vigencia como género dramático al presentarse en su forma entremesada.

Bajo esta forma dialogada y por lo que respecta a la loa cortesana

26 Como apunta Mercedes de los Reyes: «La loa, escrita para la ocasión, se acomoda, como pieza de circunstancias, al acontecimiento que se celebra y al auditorio, cuya benevolencia se capta mediante los repetidos tópicos de la humildad de los personajes ante tan altos destinatarios y de la imposibilidad de loarlos con justeza. Un auditorio que $[. .$.$] queda claramente configurado y se introduce en la pieza, produ-$ ciéndose una perfecta simbiosis entre el plano de la ficción y el de la realidad» (De los Reyes, 1994, p. 60). 
y de casas particulares, el modelo constructivo gira habitualmente en torno a un debate de méritos entre una serie de personajes alegóricos (normalmente en series de dos, tres o cuatro) que pugnan por obtener el patrocinio de la celebración (Mérito, Fortuna, Aurora, Alegría, Edad, Día, Poesía, Pintura, Historia...). En el caso de las loas religiosas y sacramentales, «inicialmente no es rara la descripción de la fiesta del Corpus o unas disquisiciones ingenuas entre figuras campestres sobre la presencia real de Cristo en la Eucaristía; después se multiplican polémicas filosóficas o teológicas $»^{27}$. En lo que atañe a las loas de corral y de presentación de compañía, la discusión entre los distintos actores, que en la nómina de personajes suelen intervenir caracterizados como tales, el debate se transforma más bien en un desfile de entradas y salidas a escena en el que los actores hacen ostentación de sus virtudes actorales. La competencia se resuelve cuando se han escenificado los méritos de actuación de todos los actores/personajes que integran la compañía teatral, lo cual remite, en última instancia, a un elogio práctico de sus méritos ante la nueva temporada teatral que comienza.

En todos los casos, los ejes de contraste que determinan la discusión se combinan dilógicamente en el nivel espectacular y el textual. Por ello son habituales, en el nivel de la puesta en escena, las salidas laterales por cada uno de los lados del tablado; las oposiciones por el nivel vertical del descenso desde lo alto y el horizontal del tablado; los efectos musicales de contraste entre canto y recitado; la distinción entre luz y oscuridad, etc. En el nivel textual destacan las estructuras paralelas en las réplicas y contrarréplicas; plurimembraciones; antítesis; paralelismos; metáforas y alegorías; el uso de la diseminación/recolección de argumentos, etc.

Sobre los personajes protagonistas recae el peso de la argumentación, y los valores que representan se convierten en los ejes temáticos que focalizan las vías del elogio. El desarrollo del debate conduce hacia una solución igualatoria que incluya todas las vías argumentativas, es decir, que combine todas las fórmulas panegíricas inicialmente enfrentadas en la discusión. Aunque el enfrentamiento suele resolverse con la salida a escena de un juez mediador en la disputa, que por su propia definición simbólica pueda contener los méritos de

27 Spang, 1994, p. 17. 
los personajes enfrentados (por ejemplo, la Alegría, el Amor, el Día...). Los protagonistas se ven asistidos por sus respectivos coadyuvantes, quienes se presentan en un segundo nivel de la discusión y cuya función es la de asistir a sus respectivos personajes regentes en el debate; personifican en el escenario las razones desarrolladas en la discusión hasta su entrada o, en algunas ocasiones, introducen nuevos tramos argumentativos. Pueden presentarse bajo la forma abstracta de coro (coro de ninfas, coro de planetas, coro de luces...), como personajes integrados en un colectivo de tradición simbólica tipificada -Elementos, partes del día, partes del mundo...- o individualizados en la forma de un personaje alegórico - Atención, Rendimiento, Afecto...-. Su aparición suele darse en la segunda parte de desarrollo del debate y se caracteriza por su componente espectacular, puesto que su salida al escenario focaliza un nuevo punto de atención en el tablado y completa el cuadro espectacular de la discusión. De ello se deriva también su secundaria función ambientadora.

La síntesis simbólica a la que tiende la solución conciliadora de la discusión de méritos propugna una visión poliédrica del elogio, que surge de la combinación de las distintas analogías panegíricas. En efecto, la formulación analógica de la reivindicación de cada personaje sobre su pertinencia en la conmemoración de la circunstancia implica, según la alegoría de sus méritos, una propuesta laudatoria respecto al destinatario del elogio. La analogía domina el principio estructural del debate en el que sus participantes muestran el propósito de equiparación e igualación de méritos en la formulación simbólica del elogio.

El asunto dramático de la loa se dispone en una estructura tripartita según las convenciones clásicas de introducción, desarrollo y desenlace. Así pues, el debate de méritos, como principio estructurador de la diégesis dramática, se configura según los parámetros que impone la función panegírica de la loa. La discusión de razones entre una serie de personajes que pugnan por obtener el mecenazgo de la celebración implica una dignificación de sus atributos simbólicos según las directrices del elogio, ya que la declaración de los motivos que justifican su pertinencia en el asunto denota la trascendencia, no solo de la circunstancia, sino también del personaje homenajeado que la inspira. La introducción, como parte inaugural de la representación, cumple su función prologal desde todos los niveles que integran y definen 
la ficción dramática. Debe considerarse como preámbulo de la representación desde el eje escenográfico de la puesta en escena; desde el simbólico de la dramaturgia del elogio y, por último, desde el estructural del planteamiento de las relaciones diegéticas de los personajes presentes en el tablado.

La segunda parte de desarrollo del debate, como preludio de la síntesis festiva del desenlace y tras la apertura espectacular de la subida del telón, traza unas expectativas distintas, que centran su poder de evocación en el despliegue de las formas de argumentación. La intervención de los coros de coadyuvantes es otro de los rasgos propios de esta segunda fase de desarrollo del debate. Este último aspecto nos permite subrayar la interacción entre el nivel retórico de la argumentación y el espectacular de la puesta en escena, ya que su aparición en el tablado implica una visualización en escena de las razones de la discusión.

La tercera parte de la loa combina tres segmentos dramáticos que representan sus tres funciones básicas de clausura. El primer segmento resuelve el debate de méritos en el que se enfrentaban los personajes protagonistas por obtener el mecenazgo de la celebración. El segundo se dedica a presentar la comedia que seguirá a continuación y, por último, el tercer segmento dramático o ultílogo elabora una síntesis panegírica final en la que se celebra la ocasión y los personajes homenajeados.

En el caso de las de corral y de presentación de compañía, como apuntábamos anteriormente, la discusión se plantea mediante la escenificación de un desfile de las competencias de cada actor de la compañía, por lo que no se puede apreciar directamente la distinción propiamente dicha entre protagonistas y coadyuvantes, aunque sí, según los casos, la misma composición de la compañía teatral determina la mayor o menor preponderancia de los actores/personajes en escena. Los pretextos para esta puesta en escena de los méritos de la compañía suelen ser habitualmente dos. Un primer argumento dramático se presenta bajo la desesperación del autor de la compañía, quien aparece en escena para confesar que ante la inminente presentación de la compañía en la ciudad, sus actores se han vuelto locos. La locura viene dada por el desempeño y la aplicación que estos han mostrado ante la responsabilidad que implica esa presentación y, de tanto ensayar, han acabado por creerse, en «realidad», los papeles 
que deben representar en las tablas. En todos los casos, la sola mención de la ciudad en la que se está llevando a cabo la representación hace que los actores retomen su cordura, encomien el lugar y den paso a la comedia que seguirá a continuación. Otra forma de argumento se presenta cuando el desfile de los actores forma parte de la escenificación del sueño del autor de la compañía cuando se duerme pensando en ese estreno y despierta ante el inminente inicio de la representación.

Uno de los referentes fundamentales en la formulación dramática de la loa a partir de la segunda mitad del siglo XVII, debe ser, necesariamente, Calderón de la Barca y, en particular, sus ocho loas para las fiestas palaciegas de las que tenemos noticia: Los tres mayores prodigios $^{28}$, Andrómeda y Perseo ${ }^{29}$, El laurel de Apolo ${ }^{30}$, El golfo de las sirenas ${ }^{31}$, La púrpura de la rosa $a^{32}$, El hijo del sol, Faetón ${ }^{33}$, Hércules o Fieras afemina

${ }^{28}$ La fiesta tuvo lugar la noche de San Juan de 1636 (Schizzano, 1987, p. 227).

${ }^{29}$ La fiesta se representó el 18 de mayo de 1653 por iniciativa de la infanta María Teresa para celebrar el reestablecimiento de la Reina Mariana de Austria. Para más detalles ver Mckendrick (1994).

${ }^{30}$ La representación estaba prevista para los carnavales de 1657, ver Sage (1956), Chapman (1954) y Cardona (1983). Aunque Lobato apunta que "con motivo del nacimiento del príncipe Felipe Próspero, se hizo la loa para El laurel de Apolo de 396 versos, que aunque se compuso para ser representada en la Zarzuela el 20 de noviembre de aquel año [1657], ese día nació el Príncipe Felipe Próspero y se retrasó la fiesta hasta el 4 de marzo de 1658 — lunes de Carnestolendas - en que se hizo en el Real Palacio del Buen Retiro, según se indica bajo su título en la princeps de la Tercera parte, impresa en 1664, en presencia de Felipe IV y de las infantas María Teresa y Margarita» (Lobato, 2000, p. 39).

${ }^{31}$ La fiesta se representó en el Palacio de la Zarzuela el 17 de enero de 1657 (Mckendrick, 1994, p. 245).

${ }^{32}$ Se representó en 1660 para conmemorar el matrimonio de María Teresa de Austria, hermana de Felipe IV, con Luis XIV, y la consiguiente Paz de los Pirineos. Para más detalles ver Cardona (1983) y (1992).

33 Según Lobato, «sobre la fecha de su estreno existen dos hipótesis principales: Cotarelo en su Historia de la Zarzuela dio como fecha de la primera representación del Faetón el 1 de marzo de 1661 en el Coliseo del Buen Retiro, por parte de las compañías de Juana de Cisneros y Diego Osorio de Velasco, para celebrar el restablecimiento del príncipe Felipe Próspero, como atestigua la loa: «a entregarle yo a la 
Amor $^{34}$ y Hado y divisa de Leónido y Marfisa ${ }^{35}$. Por ello, nos ocuparemos, en esta ocasión, de las principales estrategias dramáticas y espectaculares de la loa en su vertiente cortesana ${ }^{36}$.

La primera loa de la que se conserva el texto es la que Calderón escribió para la comedia Los tres mayores prodigios ${ }^{37}$. La loa, al igual que la comedia, se representó en tres escenarios separados, lo cual constituye una de sus primeras innovaciones. Es también una de las más extensas de las ocho loas cortesanas de Calderón se inicia con una invocación a la Noche por parte de Pales y Flora, quienes, a partir de los versos esticomíticos característicos en las aperturas del debate de méritos, reclaman su presencia para la conmemoración de la circunstancia festiva, es decir, la noche de San Juan. Su aparición por el escenario central, rodeada en los laterales por las dos ninfas ${ }^{38}$, resulta paradigmática de la estructura y la nómina de personajes propias del género, puesto que las razones de su evocación tienen que ver con la previsión del festejo que va a llevarse a cabo.

Las preguntas de Pales y Flora acerca de la comedia que va a representarse, molestas por el supuesto descuido de la Noche en los preparativos, dan pie a la aparición de los que serán sus protagonistas, Hércules, Jasón y Teseo:

Fama / una obra [...] que de su memoria es digna, / pues festivo parabién / es de aquesa mejoría». Rafael Maestre en su edición de la fiesta, reiteró esta fecha y opinó que en 1662 habría tenido lugar una segunda representación» (Lobato, 2000, p. 69).

${ }^{34}$ La fiesta celebraba el cumpleaños de Mariana de Austria y el de la pequeña María Antonia, sobrina de Carlos II. Se representó en el real Coliseo del Buen Retiro el 29 de enero de 1672 (Lobato, 2000, p. 125).

35 Se representó en 1680 con motivo del matrimonio de Carlos II y María Luisa de Orleans. Ver Mckendrick, 1994, p. 249 y Zapata, 1991, pp. 22, 224 y 227.

36 Para una visión en conjunto de todas las loas de Calderón para fiestas palaciegas ver Lobato (2000). Por lo que respecta al análisis específico de las loas de presentación de compañías, puede verse Farré $(2000,2007)$ y, en lo que atañe al estudio de la variante sacramental, las pautas ofrecidas por Rull (1994).

37 Seguimos la edición de Hartzenbusch (1944).

38 La acotación inicial precisa cómo las dos ninfas salen cada una por un escenario, mientras que el tablado central, reservado para la siguiente aparición de la Noche, queda de momento vacío: «Ha de haber tres teatros, divididos uno de otro: en el de mano derecha saldrá la Ninfa Pales; en el de mano izquierda la ninfa Flora, dejando desocupado el de en medio» (p. 263). Asimismo, la Noche, en su primera intervención, se hace eco de la esticomitia de las invocaciones de las ninfas: "Que a las voces de las dos / salgo, dejando mi albergue» (p. 263). 
Pales

FLORA

Noche
Refiérenos de qué trata.

Repítenos qué contiene.

Escuchad, que el argumento

os quiero poner presente

de toda la fiesta, a ver

lo que la fiesta os parece,

que esto hizo la Antigüedad

en sus fiestas muchas veces.

Escuchad, pues, su argumento

antes que se represente. (p. 264) ${ }^{39}$

El artificio dramático, y una de las novedades que introduce Calderón en esta loa, consiste en la puesta en escena de la síntesis argumental de la posterior comedia, ya que Jasón y Teseo, para ayudar a Hércules - desesperado por el rapto de Deyanira a manos del centauro Neso-, se ofrecen a participar en su búsqueda. Después de que Hércules acuerde distribuir sus esfuerzos —él mismo se encargará de buscar en África, mientras Teseo hará lo propio en Asia y Jasón recorrerá Europa - aparece de nuevo la Noche, asistida por Pales y Flora.

En este caso no existe propiamente una discusión de méritos entre las dos ninfas, ya que Calderón parece optar por el consenso inicial entre los dos personajes protagonistas y recalcar su oposición simbólica mediante, sobre todo, el nivel de la puesta en escena. Un aspecto a tener en cuenta es que el mismo festejo incorporaba la novedad de que cada acto de la comedia fuera representado por una compañía distinta y en un tablado diferente ${ }^{40}$, lo cual podría explicar las innovaciones introducidas por Calderón en las estrategias dramáticas y escenográficas de la loa. Además, son precisamente los rasgos de «exhibición y la originalidad» en lo referente a la puesta en escena de la

${ }^{39}$ Todas las referencias de las loas que consultamos por la edición de Hartzenbusch aparecen citadas por el número de página, ya que los versos carecen de numeración.

40 «Hubo por la noche de San Juan uno [festejo] de los más sobresalientes, por su exhibición $y$ originalidad [...] La función consistió en un drama compuesto adrede para ser representado por tres de las varias compañías teatrales de esta ciudad, siendo tan bueno el sujeto de la obra, y tan llamativo el lugar en que se la representó en tres distintos escenarios, y el alumbrado tan rico en novedad y atractivo", Schizzano, 1987, p. 227. 
fiesta, las razones sobre las que versan las alusiones metateatrales que la Noche destaca, humildemente, de su comedia:

Pales ¿Prevenida hay fiesta?

NOCHE

Sí.

FLORA ¿Y qué fiesta es?

NOCHE

La que siempre, una comedia.

PALEs

¿Hala escrito

algún ingenio escelente?

Noche No, sino pobre y humilde.

Flora Poco importará, si tiene

algún teatro que haga

evidencia lo aparente.

Noche Tampoco tiene apariencias.

Pales Pues buena fiesta previenes. (p. 263)

Tras el apóstrofe de Pales y Flora, la encargada de prevenir el festejo recreará la ilusión de realidad envolvente propia del género desdeñando los factores que sin duda serían los principales reclamos de la fiesta: el haber sido escrita por Calderón, un «ingenio pobre y humilde»; el «teatro» y las «apariencias». El mérito principal frente a los espectadores, seguramente fascinados ante la innovación de los tres escenarios, pasa a ser entonces el argumento de la comedia que se presenta ya dentro de la dramaturgia de la loa. Calderón pone en boca de la Noche, en el parlamento previo a la salida en el escenario central de Hércules, Jasón y Teseo, cómo en las fiestas de la Antigüedad el resumen del argumento era una de las prácticas habituales del género en las fiestas (véase el primer fragmento citado de la loa), aunque en esta ocasión la novedad reside en que no es recitado sino que se representa en el tablado por parte de sus protagonistas.

Apuntadas las líneas argumentales de la comedia, aparecen de nuevo la Noche y las dos ninfas. En esta tercera parte de la loa, destaca el primer parlamento de la Noche que precede a las réplicas de Pales y Flora, donde las ninfas se dirigen al público y elogian a los destinatarios: 


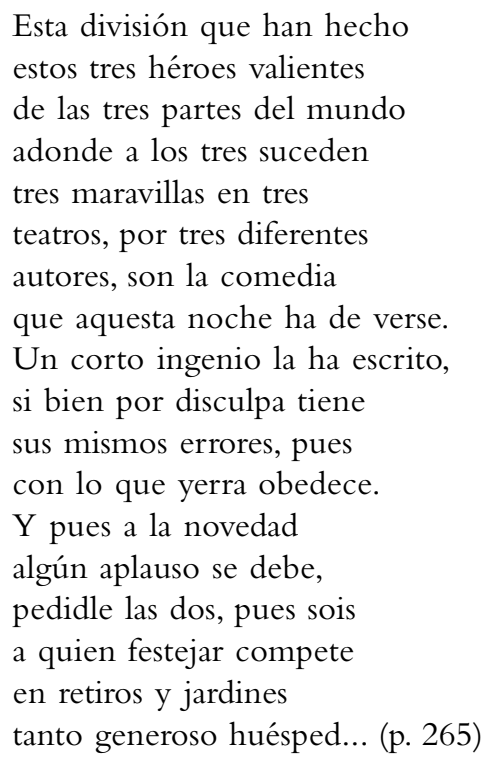

La redundancia en los paralelismos por la repetición del número tres, tan del gusto de Calderón, alcanza en esta ocasión un correlato escénico mediante la novedad de los tres teatros y, de nuevo, es una de las razones que se esgrimen en la loa como motivo de aplauso. Del mismo modo, tal y como antes la Noche se refería al autor como "pobre y humilde» (p. 263), la retórica de captación de benevolencia en el cierre insiste en el "corto ingenio» del dramaturgo. A continuación, intervienen Pales y Flora en una serie de réplicas que condensan las metáforas del elogio dirigidas a los destinatarios de la representación: Felipe IV («cuarto planeta»), Mariana de Neoburgo («de Francia divina Fénix»), el príncipe Baltasar Carlos («bello Baltasar») y la «hermosa Ana Antonia» (p. 266).

En la loa para Andrómeda y Perseo ${ }^{41}$ la Poesía y la Pintura se conciertan bajo el patrocinio de la Música para conmemorar «tan glorioso asunto» (v. 62), puesto que demuestran un «alto interés» (v. 63) en la circunstancia conmemorativa del día. La loa inicia con un fragmento previo a la subida del telón que, como en el caso de la posterior loa

${ }^{41}$ Seguimos la edición de Rafael Maestre (1994). 
para Fieras afemina Amor, supone una espectacular puesta en escena del motivo de la fiesta, la alegría por el reestablecimiento de la salud de la reina, y recrea, ya de entrada, la ilusión de una realidad envolvente en la que el público, al asistir como testigo de los preparativos que exige el "glorioso asunto», puede implicarse en la celebración del elogio. Antes de que inicie la loa propiamente dicha, la pintura del telón introduce la alusión a los destinatarios de la celebración, así como las principales claves del «jeroglífico» o asunto simbólico sobre el que Calderón trazará el argumento de la loa. De este modo, la escena presentaba a primera vista una tienda carmesí, dividida en compartimentos iguales con florones y cifras de plata, representando las iniciales de los nombres de los reyes y de la infanta María Teresa. Dos columnas sostenían un arco, en cuya parte superior se representó "un sol con algunas nubecillas, que no le deslucían, ni afeaban; y a merced de sus rayos, un país de varias flores en cuyo primer término eran de mayor tamaño un laurel y un rosal» (p. 41). El dibujo se coronaba con un fondo de cielo, en el que se leía en la parte superior la divisa latina «General Omnia», y en la inferior la castellana: «Vive tú, vivirá todo; / que no hay distancia entre ver / padecer o padecer» (p. 41). La letra castellana será el estribillo que se repita en la primera parte de la loa, hasta el verso 116, y que permita la salida a escena de la Música para la "glosa de los conceptos de la empresa» (p. 41):

\author{
Adoleció del achaque \\ de una nube el rosicler \\ del sol y todas las plantas \\ adolecieron con él. (vv. 4-7)
}

La concordia preside, de nuevo, el debate entre los personajes que, más que discutir por el mecenazgo, asumen la complementariedad de sus méritos y conciertan sus razones simbólicas para planificar el festejo: la Poesía ofrece el asunto (vv. 81-84); la Música se ocupará de esa "otra armonía en la voz / que en los humanos; que es bien / que no hablen dioses como / los mortales» (vv. 95-98) y, finalmente, la Pintura tendrá siempre «la escena conforme» (vv. 97-99). Tras este fragmento previo a la subida de la cortina (vv. 1-116), los tres personajes, suspendidos en sus respectivas tramoyas de nubes, van desplazándose hacia el centro del tablado y se disponen a subir el telón. 
En el escenario se descubre a Atlante, quien sostiene una enorme y pesada esfera y, al mismo tiempo, aparecen suspensas en el aire doce ninfas que simulan los doce signos del zodíaco. El artificio que han dispuesto la Música, la Poesía y la Pintura, es decir, la forma espectacular que dramatiza la loa, consiste en una alegoría escénica en la que Atlante representa a Felipe IV, «el que el globo sustenta / del Orbe todo» (vv. 157-158). El pesar por los achaques de Mariana de Austria es simbolizado en la preocupación que presenta Atlante, «rendido al peso / de un pesar solo» (vv. 159-160). Así pues, la mejoría en la salud de la reina implica que Atlante, como sucede en el desenlace, pueda erigirse como gigante — a partir del verso 168- y trascender la metáfora espectacular del amor por su esposa y, al mismo tiempo, su grandeza en el orbe como monarca. Para finalizar, el ultílogo desarrolla un canto coral en el que son exhibidas las metáforas de cortesía propias del género, dedicadas a cada uno de los miembros de la familia real. En el cierre, destaca la metáfora del aplauso como alusión a la función circunstancial de la loa y que constituye uno de los símbolos tópicos del género ${ }^{42}$ :

\author{
Ya que aplauso esta fiesta \\ por sí no tiene, \\ téngale el respeto \\ de quien la ofrece. (vv. 180-183)
}

La celebración del nacimiento del príncipe Felipe Próspero es el asunto que inicialmente conmemora la loa para El laurel de Apolo ${ }^{43}$. Las estrategias dramáticas que exhibe la loa se organizan en torno a las intervenciones de las ninfas Iris y Eco, quienes desean actualizar y publicar la magnitud de dicho acontecimiento festivo. La loa se inicia con un parlamento cantado de Iris, cuyo estribillo

Todos hoy se alegren, pues hoy con próspero arrebol para todos nace el Sol. (p. 656)

${ }^{42}$ Ver, Farré, 2000, vol. 1, pp. 32 y ss.

43 Seguimos la edición de Hartzenbusch (1945). 
es el pretexto para la salida a escena, también cantando, de la ninfa Eco:

\author{
¿Qué te mueve a dejar hoy \\ el triunfal arco y que dulce \\ lo que fue matiz, sea voz \\ obligándome a que diga \\ $[\ldots]$ \\ que hoy todos se alegren, pues \\ hoy con próspero arrebol \\ para todos nace el sol? (p. 656)
}

Tras la presentación de las dos ninfas, por medio de la publicación de la circunstancia festiva, lo siguiente consiste en la recreación de una realidad envolvente. Es decir, planteadas las coordenadas simbólicas del elogio en el eje temporal, la segunda parte de la loa se centrará en escenificarlas en el eje espacial, a partir de la invocación de cuatro coros que representan las cuatro partes del mundo. Cada uno está compuesto por dos damas y dos galanes: los de Asia van de máscara vestidos a lo judío, portando tarjetas en las manos con la cifra del nombre de Felipe; los de África salen de máscara vestidos a lo moro con mascarillas negras y hachas en las manos; los de América aparecen vestidos a lo indio y con ramos en las manos y, por último, Europa sale representada por un coro de españoles. Las razones simbólicas sobre las que se concierta este desfile de coros son escenificar la implicación del orbe y de las cuatro partes del mundo, lo cual denota un espacio de gloria ilimitado y absoluto (Asia, África, Europa y América) sometido a las "plantas» del príncipe (p. 656) y que remite a una de las estrategias básicas del género, la actualización de los ejes alegóricos del elogio mediante su materialidad escénica.

El desarrollo de la estrategia panegírica es interrumpido por la aparición de la Zarzuela (p. 656), quien, con su «rústica simpleza», también desea ofrecer «de su amor muestra». Su presentación es interpretada por los coros de ninfas como un intento de "competencia» (p. 656), por lo que la Zarzuela desarrollará sus razones de implicación en un extenso parlamento, cuya función consiste en enfatizar la dimensión del día y, de este modo, actualizar en el presente de la representación los motivos panegíricos de la fiesta: 


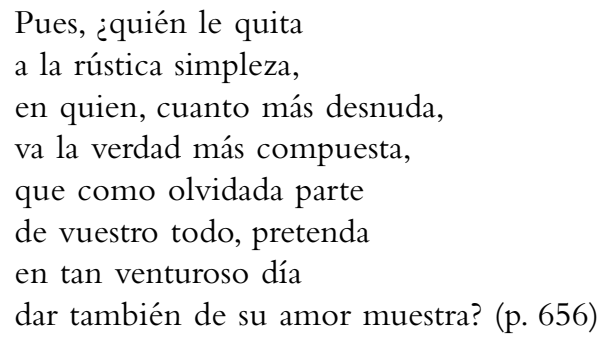

En el debate, la Zarzuela se ve increpada por las sucesivas réplicas de cada coro, que le recriminan su intento de competencia en la celebración. Su argumentación es presidida por el deseo de concordancia entre la condición católica del Príncipe y las estrategias laudatorias pertinentes, de acuerdo con el decoro que exige «el que nace a ser defensa / de la cristiana milicia» (p. 656). En virtud de ello, la Zarzuela reivindica la religión como su mayor herencia, aunque el argumento final por el que merecerá el patrocinio de la celebración será la asistencia simbólica de

\author{
La hermosa María Teresa, \\ en quien más noble, más digna, \\ más heroica, más suprema \\ y más generosa vive \\ la verdad de la fineza \\ con que esta ventura aplaude, \\ con que esta dicha celebra. (p. 656)
}

El desenlace del debate, tras la réplicas de los coros y los extensos parlamentos de contrarréplica de la Zarzuela, propicia que sea el coro de Europa el que ponga de manifiesto que

\author{
Aunque la razón del culto \\ por ahora no nos mueva, \\ la de la cortesanía \\ a todos nos hace fuerza \\ para que no solo demos \\ primer lugar a tu fiesta, \\ pero para que seamos \\ quien te ayude. (p. 656)
}


Tras el acuerdo festivo y la aceptación del patrocinio de Zarzuela, a quien asistirán las cuatro partes del mundo, se sucede el ultílogo, donde pueden observarse todos los tópicos propios del desenlace. En primer lugar, la introducción al género de la pieza larga a la que precede la loa, en este caso zarzuela: «No es comedia, sino solo / una fábula pequeña / en que, a imitación de Italia, / se canta y se representa» (pp. 656-657). Tras presentar también su asunto y título, siguen las alabanzas tópicas a todos los miembros de la familia real y, en último lugar, a las damas del auditorio. Destaca en esta parte cómo se engastan el final de la loa y la introducción de la zarzuela mediante la intervención inesperada desde dentro de nuevos personajes. A las voces que presentan el paisaje ( $\mathrm{A}$ lo llano. $\mathrm{Al}$ monte. $\mathrm{Al}$ valle. / A la selva», p. 657), se superpone la queja de Dafne, que se repetirá literalmente en la primera escena de la zarzuela: «¿No hay quien me socorra? / ¿No hay quien me defienda?» (p. 657). La sorpresa por parte de todos los personajes visibles en el tablado ante la escena que se recrea mediante las voces desde dentro, da pie a la explicación de Zarzuela:

\author{
Que entiendo, \\ si bien se me acuerda, \\ que pues la loa acaba, \\ la fábula empieza. (p. 657)
}

Para finalizar, Eco e Iris, retomando la escena inicial que enmarcaba el desfile de los coros de las partes del mundo, propician el baile final de cierre con el que se termina la loa.

La loa para El golfo de las sirenas ${ }^{44}$ se inicia con una escena doméstica entre el rústico pescador Alfeo y su esposa, la villana Celfa, en la que discuten acerca de los rigores que impone el frío del invierno en el mar y el campo. Su diálogo adquiere una inesperada trascendencia simbólica cuando, desde dentro, los cuatro Elementos ratifican en réplicas cantadas los efectos del clima en sus respectivos dominios de referencia. La secuencia se cierra con una síntesis recopilatoria:

${ }^{44}$ Seguimos la edición de Hartzenbusch (1945). 
Que porque el enero con ellos embiste las flores se pasman, los rayos tiritan las ondas se quejan, los pájaros gimen. (p. 617)

La repetición que los Elementos exponen por medio de la diseminación/recolección de las principales imágenes acerca de los rigores del frío enlaza con otra secuencia dramática que, inicialmente desde dentro, será protagonizada por Astrea y Sileno. Calderón introduce un nuevo nivel de oposiciones que, a partir de las pautas de la escena inicial entre Celfa y Alfeo, superpone otra secuencia dramática paralela en la que Astrea y Sileno, saliendo cada uno por un lado del escenario, invocarán respectivamente a villanos y pastores. El parlamento de Astrea (pp. 617-618) reproduce algunos de los rasgos propios del género, ya que la descripción del locus amoenus, como lectura simbólica de la escenografía, así como del amanecer mitológico, sobre el que se proyecta el eje temporal de la puesta en escena, son las estrategias para recrear la ilusión de una realidad envolvente en la que la puesta en escena representa icónicamente las coordenadas del elogio a la familia real, destinataria de la fiesta. Astrea se lamenta de que una serie de

\author{
festivas carrozas, llenas \\ de hermosos coros de ninfas, \\ cuyas divinas bellezas \\ a desagraviar sin duda \\ vienen a la primavera, \\ restituyendo a los campos \\ cuantos matices grosera \\ robó de enero la saña. (p. 618)
}

La transformación del paisaje es posible gracias al elogio dedicado a las ninfas, que más adelante se confirmará son las mujeres de la familia real. De igual modo, la siguiente intervención de Sileno (p. 618) introduce las pautas que regirán el fragmento final de síntesis panegírica y apunta las principales metáforas laudatorias referidas a Felipe IV: «Apolo destos valles»; "Cuarto Planeta»; y «montado Adonis».

Como paso previo a la clausura, los Elementos responden desde dentro en una nueva armonización del paisaje, cuya naturaleza simbólica ha sido asimilada al espacio natural que recrean los pastores ( $\mathrm{p}$. 
618). La dinamización que pretende no dilatar el inicio de la comedia se dirige, en esta ocasión, hacia la previsión del baile. La propuesta de Celfa cumple así con el deseo de finalizar con las convenciones propias del desenlace de la loa, aunque en este caso, por la ambientación carnavalesca que rodea la fiesta, predomina el aspecto festivo del «alborozo»:

\author{
¿No será mijor, porque \\ tiempo el festejo no pierda, \\ que desde luego cantando, \\ y bailando demos muestra \\ de nuestro alborozo? (p. 618)
}

Alfeo introduce el argumento de la comedia cuando presenta a Escila, la protagonista que "en estos montes se alberga» (p. 618). El acuerdo final precede al ultílogo de cierre, donde aparecen yuxtapuestas las alusiones panegíricas a los destinatarios (p. 619). El desenlace de la loa es anunciado por un efecto de ticoscopia que simula un terremoto y obliga a los protagonistas de la loa a atravesar «esa selva» (p. 619). La metateatralidad del cierre es puesta de manifiesto por el propio Alfeo, quien señala explícitamente que «aquí acabará la loa» (p. 619).

En la loa para La púrpura de la rosa ${ }^{45}$, la Alegría y la Tristeza, con sus respectivos coros, aparecen invocadas por la duda que manifiesta la Zarzuela, ya que se muestra ambivalente ante ambos sentimientos, puesto que la Alegría denota la felicidad por el matrimonio de la infanta María Teresa con Luis XIV, mientras que la segunda se hace eco del sentimiento por su partida a Francia. La quaestio girará, pues, en torno a la exposición razonada que cada uno de los dos personajes entablará para convencer a la Zarzuela de que debe compartir el estado anímico que cada uno representa: «Saber cuál de las dos / la que hoy en mi pecho reina» (p. 673). De nuevo, el argumento sobre el que girará la exposición razonada del binomio protagonista se refiere a la circunstancia que origina la fiesta. En esta primera parte del debate, los dos personajes alegóricos formulan sus réplicas en versos esti-

45 Seguimos la edición de Hartzenbusch (1945). 
comíticos a partir de la divisa «llore la Alegría, cante la Tristeza» (p. 674), lo que, junto a la intervención de sus respectivos coros, refuerza la complementariedad simbólica con la que se desarrollará la argumentación. La equiparación simbólica que muestran la Alegría y la Tristeza obliga a la Zarzuela a rogarles a las dos que le hablen «más claro» (p. 674). La petición da pie una segunda parte de debate que, como amplificatio razonada de sus méritos, se explica en función de la partida de la infanta María Teresa a raíz de su matrimonio con Luis XIV (pp. 674-675). La Zarzuela termina sin saber cómo resolver la disputa:

\author{
Aunque rústica y grosera \\ hago también en quedarme \\ hoy entre las dos suspensa, \\ sin saber determinar \\ si llorosa o si risueña, \\ el contrapesar mi amor \\ el gusto a la conveniencia, \\ es tristeza bien hallada, \\ o alegría mal contenta. (p. 675)
}

La repentina aparición del Vulgo, vestido de loco, propiciará una solución consensuada al decirle a Zarzuela que el rey «manda que a la corte vayas / y que le lleves la fiesta / que prevenida tenías» (p. 675). El desenlace se desarrollará, a partir de la divisa del Vulgo, con la recreación de las previsiones del festejo, aunque la Zarzuela admite que no es tan «fácil» disponer una fiesta. El artificio consiste en seguir el consejo del Vulgo y ofrecer una fiesta como muestra de afecto:

Que este concepto del Vulgo que tantas veces nos cuenta que el afecto hace milagros, reduzcamos a experiencia. ¿Os atrevéis, pues sois de amor mágicas ideas, en esta breve distancia que de aquí al Retiro resta, a estudiar un festín? (p. 675) 
Durante el desenlace, la Tristeza y la Alegría aúnan sus voces ya que son las propias del afecto y, además, el aspecto musical es uno de los más nuevos de los que presenta la zarzuela: «por señas que ha de ser toda / música» (p. 674). El cierre de la loa se presenta según el formato habitual, con la síntesis panegírica a los destinatarios de la fiesta y la presentación de la pieza que seguirá a continuación, lo cual, como suele ser habitual en estas loas de Calderón, recurre a las alusiones metateatrales que hacen hincapié en sus aspectos más novedosos.

La loa que precede a la fábula escénica El hijo del sol, Faetón ${ }^{46}$ empieza, frente al telón, con dos damas que representan ser la Poesía y la Historia y que, en cláusulas esticomíticas, van respondiendo a la Música que, desde dentro, las guía para revelarles el enigma (v. 24). Los «ocultos misterios» que cifra la Música (v. 26) las conducen hasta el Templo de la Fama, a cuyas puertas encuentran dormida a la Lealtad, «de España / siempre amante y siempre fina / con mis reyes» (vv. 63-65). Puesto que es la Lealtad la encargada de guardar las llaves del Templo de la Fama, su parlamento de presentación será también el que revele las razones de la inquietud que mostraban las dos protagonistas iniciales. Así pues, el motivo inicial del sacro laurel que "sentía tocadas sus hojas» (v. 93), asunto repetido en los versos iniciales de la loa (vv. 1-10), simboliza la circunstancia que origina el festejo palaciego, la mejoría de salud del príncipe Felipe Próspero. De nuevo, el asunto festivo se confunde con el argumento dramático de la loa para convertirse en el pretexto sobre el que recrear la puesta en escena del elogio a los destinatarios de la representación.

Planteadas las coordenadas panegíricas del asunto dramático, la Historia y la Poesía procederán, respectivamente, a glosar la genealogía de los Austrias (vv. 122-131) y su alegoría (vv. 132-143) para que el príncipe Felipe Próspero, restablecida su salud y por sus propios méritos, reciba el «festivo parabién» (v. 143) que le corresponde. Asumida la pertinencia de los dos personajes alegóricos en la conmemoración festiva del día, se inicia la segunda parte de la loa en la que se descubrirá el telón y los dos personajes alegóricos procederán a entrar en el Templo de la Fama, que se representará a partir de una galería de estatuas alusivas a la genealogía de la Casa de Austria, desde Rodolfo

46 Seguimos la edición de Maestre (1996). 
I de Habsburgo hasta Fernando III (vv. 187-293). La ilusión de una realidad envolvente se consigue en esta ocasión a partir de la dramatización de una historia poética de la genealogía de los Austrias, hasta Felipe Próspero, que por medio de la contemplación de las estatuas del escenario, permite que diversos personajes alegóricos la vayan esbozando frente al público asistente a la representación. De este modo, la Fama, acompañada por la Fe, la Dicha, la Hermosura, la Guerra, la Paz, la Prudencia, la Piedad y la Ciencia (vv. 187-293) presidirá el desfile de los ilustres antecedentes hasta llegar al príncipe Felipe Próspero. Se inicia entonces la tercera parte de desenlace de la loa con la cláusula final que pronuncia la Fama y con la que se cierra la discusión de los méritos genealógicos del destinatario:

Haré un compuesto en que en él

vea el cielo que se cifran

Fe, Dicha, Gracia, Paz, Guerra,

Prudencia, Ciencia y Justicia. (vv. 312-315)

Y, tras la conciliación de todas las virtudes loadas, la Poesía y la Fama dan pie al cierre de la loa retomando la escena inicial con la Lealtad y repitiendo el estribillo inicial pronunciado por la Música desde dentro:

\author{
DAMA I $\quad[\ldots]$ desde aquí \\ Las voces de todos digan, \\ como en principio de fiesta, \\ el alma de aquel enigma \\ a quien la Lealtad de España \\ corrió antes la cortina. \\ FAMA Sí dirán, que interesadas \\ todas es bien que repitan.... \\ Música A la sombra del laurel, \\ [Y ToDos] no temas, vasalla flor, \\ del cierzo el soplo cruel, \\ que presto vendrá el favor \\ del austro que inspira en él. (vv. 333-344)
}


La loa para la comedia Fieras afemina Amor se inicia con un fragmento previo a la subida del telón y, gracias a la acotación inicial que describe la cortina ${ }^{47}$, podemos hacernos una idea de la magnificencia sobre la que se llevará a cabo su puesta en escena, ya que sus protagonistas serán el Águila, el Fénix y el Pavón, asistidos por los doce signos del Zodíaco y los doce meses del año. Es decir, la nómina de personajes asciende a veintisiete, además de contar con la presencia de los músicos - la loa, tras su espectacular subida del telón, combina fragmentos de canto y recitado- La preeminencia del Águila sobre el Fénix y el Pavón resulta evidente desde el inicio, no solo por su posición central en el escenario y por su definición simbólica (vv. 1-26), sino también porque se trata del personaje que dio principio a la loa para anunciar el motivo del festejo: «los felices años / del Águila suprema» (vv. 9-10), y convocar al Fénix y al Pavón para exponer las razones simbólicas para participar en el festejo. Tras unas réplicas de presentación desde dentro (vv. 27-34), el primero que sale a escena es el Fénix y su principal argumento es el de simbolizar el amor:

\author{
Símbolo del amor es \\ el Fénix que, en blanda hoguera, \\ fuego nace, fuego muere \\ y fuego otra vez se engendra. \\ Luego si afectos de amor \\ son los que a todos alientan, \\ y el amor llama que nace \\ hija y madre de sí mesma,
}

${ }^{47}$ La vista del pórtico del teatro se fundaba sobre cuatro columnas que imitaban piedra lázuli, con cañas adornadas a trechos de resaltados bollos de oro y capiteles y basas dorados. El frontis se cerraba con una medalla guarnecida de hojas de laurel con cuatro mascarones y otros adornos que la dividían en igual compartimiento, y en la que se representó un Pegaso con un galán joven que representaba a Mercurio. A los lados del pórtico, en dos nichos estaban dos estatuas que imitaban el bronce, una con un león y la otra con un tigre, que significaban el valor y la osadía. Todo este frontispicio se cerraba con una cortina en la que, en primer término, se veía a Hércules, con las fieras vencidas a sus plantas, y, en el segundo término, Cupido flechando el dardo, "que en el asumpto de la fiesta había de ser desdoro de sus triunfos», como apuntaban los dos motes de la inscripción: «Fieras afemina Amor» y «Omnia vincit amor». 
en festejos de años nadie hay que pueda asistir como el ave que los renueva. (vv. 35-44)

A continuación, también cantando, la ninfa que personifica al Pavón defiende sus méritos para patrocinar el festejo como símbolo de la vigilancia (vv. 45-58) y, en su divisa final, concluye: "Conque, en fiesta de años de quien gobierna, / ave que toda es ojos, que asista es fuerza» (vv. 57-58). Tras esta primera presentación cantada, ambos personajes invocarán a sus respectivos coros de coadyuvantes para que personifiquen en escena las principales razones simbólicas de sus méritos en la celebración. De este modo, el Fénix convoca a los doce meses (vv. 68-78) y el Pavón a los doce signos (vv. 79-90). Calderón, como antesala al enfrentamiento entre los dos protagonistas, pone en boca del Águila, el juez mediador en la disputa, una solución conciliadora, previa a la aparición de los coadyuvantes, en la que pone de manifiesto la complementariedad de ambos oponentes y sobre la que se concierta la aparición de los coros de coadyuvantes:

Luego mirando a un fin mesmo

las solicitudes vuestras,

sin que en los medios se estorben

puesto que de una es la tierra

teatro, de otra teatro el cielo,

fácilmente estáis compuestas. (vv. 91-96)

Asumido pues el «afecto» de ambas aves (v. 98), se inicia, a partir del verso 139 , y tras haberse descubierto el tablado ${ }^{48}$, la salida de cada

48 La acotación lo describe de la siguiente manera: «dejando descubierta la primera scena del teatro. Era su prespectiva de color de cielo hermoseado de nubes y celajes, y desde su primer bastidor hasta su foro, cuajadas de caladas estrellas que al movimiento de artificiales luces, obscureciendo unas y brillando otras, en luciente travesura campeaban alternadas; sobre cuya vistosa inquietud de sombras y reflejos, estaban en el aire los doce signos significados en doce hermosas ninfas: tenía cada una en la una mano, dibujado en trasparente escudo, su carácter, y en la otra una antorcha de cuya llama descendía un rayo de velillo de plata que, como influjo que inspiraba en ellos, le admitían los doce meses, significados también en doce airosos jóvenes que, al pie cada uno de su signo, formaban entre todos, en dos bandas cuatro diagonales líneas tiradas al centro con tan regular medida en su declinación las esta- 
uno de los meses acompañado de su respectivo signo regente (vv. 139315), intentando cada uno lograr prevalecer sobre el otro. Trasladada la competencia a los coros, el debate se resuelve con la reivindicación de Diciembre, que pretende obtener el mecenazgo por su carácter austral:

\author{
Luego al Diciembre, que es \\ quien solo lo austral alega, \\ se le debe la guirnalda; \\ que a la voz de ave que vela \\ $\mathrm{y}$ de ave que es toda amor, \\ el águila real presenta \\ hoy al águila imperial \\ cuando... (vv. 353-360)
}

El resto de meses y signos le recriminan su intento al reprocharle ser el mes con menos luz de todos, a lo que se defiende Diciembre por ser el mes en el que nació Mariana de Austria (vv. 371-378). Así pues, en esta recreación de una realidad envolvente y simultánea al desarrollo dramático de la loa, la circunstancia festiva se convierte en el argumento final para la solución de la competencia entre meses y signos. La música certifica el consenso: «Pues que nos da mejor sol / Diciembre en mejor esfera, / que viva, que reine, que triunfe y que venza» (vv. 413-415), que permite el baile final de cierre de «guerra amorosa» (v. 429).

La loa que precede a Hado y divisa de Leónido y Marfisa ${ }^{49}$ presenta una elaborada escenografía y, como en otras loas de Calderón, un complejo juego inicial entre la espectacularidad del telón para descubrir el escenario y una cuidada apertura musical ${ }^{50}$. La estructura sigue, de nuevo, las pautas habituales del género: la Poesía y la Historia muestran su extrañeza por los ecos que suenan entre bastidores:

tuas que, desmentidas unas de otras, dejaban verse todas. No fue menor adorno desta vistosa planta lo ataviado della, pues así las tres que corrieron la cortina, como los signos, los meses y los músicos que también acompañan a lo lejos, estaban todos uniformemente vestidos de azul y plata, con rizados penachos de plumas, blancas y azules».

49 Seguimos la edición de Hartzenbusch (1945).

${ }^{50}$ Para un análisis pormenorizado ver el estudio de Neumeister (1979). 


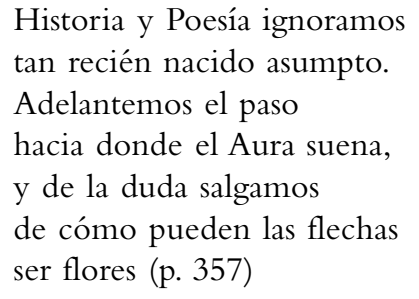

Su curiosidad se convierte en el argumento sobre el que versa el encomio a Carlos II y a María Luisa de Orleans y la divisa festiva, ya inscrita en el telón — «Flechas que tan dulces hieren / al llegar al corazón / flores, que no flechas son" (p. 356)—, será el pretexto para un diálogo entre la Historia y la Poesía, visibles en el tablado, y la Música-Aura, que desde dentro responde a sus invocaciones. Así pues, no existe un conflicto dramático y, de nuevo, las razones sobre las que se organiza el festejo pasan a ser el pretexto dramático para una puesta en escena que, en el caso de Calderón, alcanza un elaborado nivel de espectacularidad. La retórica del encomio no sufre variaciones, aunque su complejidad hará que tanto la Poesía como la Historia reclamen a la Música que hable «más claro» (p. 357), a pesar de que la primera confiesa que alcanza «tan alto empleo de la metáfora» (p. 357) mientras que la segunda declara que ha entendido "el disfraz / de assumpto tan soberano» (p. 357). La claridad que reclaman ambas al Aura, ya presente en el escenario, da pie a la salida del Clavel y la Azucena, quienes asumen en escena su condición de personajes alegóricos y se presentan, claramente, como metáforas alusivas a los reyes:

Clavel El clavel, de las flores

rey coronado,

ya lo ha dicho en las bellas

señas de Carlos.

Azucena La azucena, de flores

reina divina,

ya lo ha dicho en las señas

de María Luisa. (p. 357) 
La presentación de estos dos nuevos personajes propicia el desarrollo de la siguiente parte de la loa, en donde se descubrirá el telón para mostrar un pabellón que simulaba el Templo de la Fama. La tópica panegírica se construye en la oposición cromática entre el blanco de la azucena, con el que se identifica a la Reina, y el rojo del clavel que se refiere a Carlos II. Los dos colores distinguen las dos formulaciones retóricas en el elogio a los reyes, ya que el fin último de la loa consiste en equiparar la grandeza de los Austrias y la de los Borbones, cuya glorificación igualatoria de los antepasados de ambas familias se llevará a cabo en la presentación de los antepasados más gloriosos que aparecen en el Templo de la Fama (p. 358). Las estrategias dramáticas se relacionan estrechamente con las que exhibía la loa para El hijo del Sol, Faetón, ya que en aquella ocasión el Templo de la Fama era el espacio en el que historiar poéticamente la genealogía de los Austrias y presentar los antecedentes de Felipe Próspero como punto de unión de las dos familias que representaban Felipe IV y Mariana de Austria. Las estrategias panegíricas en el cierre siguen los parámetros habituales y los «aplausos nupciales» que deben aportar «futuras sucesiones» (p. 358) cifran el elogio final. La Fama, antes del baile final de cierre, pronuncia la sentencia con la que se anuncia el inicio de la Fiesta y la comedia que seguirá a continuación:

\author{
Dad principio, por si es larga, \\ y ese real aparato \\ encubran nubes, pues ya \\ su alfombra son esos astros, \\ a quien la música sigue \\ sonora en acentos blandos. (p. 358)
}

El repaso a las loas para las fiestas palaciegas de Calderón demuestra cómo el estudio de las loas puede convertirse, desde luego, en un sugerente campo de estudio en el que explorar diferentes aspectos de la evolución del teatro durante el siglo XVII, desde la reflexión metateatral acerca de los registros y circunstancias de la actuación, hasta la configuración de las estrategias simbólicas para el encomio de reyes y nobles, pero asimismo debe contemplarse que, en el marco de 
la profesionalización del teatro barroco como espectáculo y como negocio, el momento inicial para establecer la connivencia con el público, previo pago de su entrada, también se tipifica según unas nuevas leyes de oferta y de demanda.Ya no es necesario que al iniciar la representación la loa se centre tan solo en pedir silencio al público o resumir el argumento, sino que la nueva demanda pasa por la codificación de otros mecanismos de captación de interés. La oferta pasa inicialmente por una nueva morfología dramática, distinta del monólogo recitado vigente durante el siglo XVI y parte del XVII, en la que el género adquiere pleno estatus espectacular a partir de su forma dialogada. El horizonte de expectativas del público del XVII demanda, pues, un formato espectacular en el que a partir de la ilusión dramática de una realidad envolvente que se presenta como simultánea al desarrollo de la acción escénica, ser testigo presencial del espectáculo desde su misma realidad intraespectacular. Por ello, y para concluir, creo que es necesario trazar el itinerario de la loa a partir de esa misma realidad intradramática y codificar su tipología genérica desde los mismos recursos instraespectaculares a los que apela en su función inaugural de la puesta en escena y de captación de benevolencia, es decir, desde la convención dramática de una realidad envolvente que pretende recrear una simultaneidad de la puesta en escena, justo en ese momento fronterizo en el que se inicia la ficción dramática. Desde esa perspectiva y, tal como sucede para el estudio de las demás formas de teatro breve, puede trazarse una morfología del género según los espacios y circunstancias de representación en la que, a partir del modelo argumentativo de debate de méritos, distinguir las variantes de la loa de corral, loa sacramental y loa de corte y casas particulares. 


\section{Bibliografía}

Allen, J. L., "Los espacios teatrales», en Historia del teatro español. De la Edad Media a los Siglos de Oro, Madrid, Gredos, 2003, vol. I, pp. 629-653.

Antonucci, F. y S. Arata, La enjambre mala soy yo, el dulce panal mi obra. Veintinueve loas inéditas de Lope de Vega y otros dramaturgos del siglo XVI, Sevilla, UNED / Universidad de Sevilla / Universitat de València, 1995.

Calderón de la BARCA, P., «Loa para la comedia Los tres mayores prodigios», en Comedias, ed. J. E. Hartzenbusch, Madrid, Atlas, 1944, BAE, t. VII, pp. 263-266.

- «Loa para Andrómeda y Perseo», en Andrómeda y Perseo, ed. R. Maestre, Almagro, Museo Nacional de Teatro, 1994, pp. 41-48.

- «Loa para la zarzuela de El laurel de Apolo», en Comedias, ed. H. Hartzenbusch, Madrid, Atlas, 1945, BAE, tomo IX, pp. 655-657.

- «Loa para la égloga piscatoria de El golfo de las sirenas», en Calderón, P., Comedias, ed. H. Hartzenbusch, Madrid, Atlas, 1945, BAE, tomo IX, pp. 617-619.

- «Loa para la comedia La púrpura de la rosa», en La púrpura de la rosa, ed. T. de Torrejón, Á. Cardona, D. Cruickshank y M. Cunningham, Kassel, Reichenberger, 1990, pp. 147-163.

— «Loa para El Faetonte», en Calderón, P., El Faetonte. Fábula escénica, ed. crítica y escenotécnica de R. Maestre, Madrid, Consejería de Educación y Cultura del Ayuntamiento de Madrid, 1996, pp. 3-16.

- «Loa para la comedia Fieras afemina Amom, Alicante, Biblioteca Virtual Miguel de Cervantes, 2001. Edición digital a partir de la Quinta parte de las Comedias de Don Pedro Calderón de la Barca, Barcelona, Por Antonio la Cavallería, 1677.

- "Loa para la comedia Hado y divisa de Leonido y Marfisa», en Hado y divisa de Leonido y Marfisa, en Calderón, P., Comedias, ed. H. Hartzenbusch, Madrid, Atlas, 1945, BAE, tomo XIV, pp. 355-359.

Cardona, Á., «Función de la música, la voz humana y el baile a través de los textos de El laurel de Apolo (loa para la zarzuela y zarzuela) y a través de la loa La púrpura de la rosa», en Calderón. Actas del Congreso Internacional sobre Calderón y el teatro español del Siglo de Oro, ed. L. García Lorenzo, Madrid, CSIC, vol. II, 1983, pp. 1077-1089.

- "La púrpura de la rosa y su ambiente teatral y musical», en Homenaje a K. y R. Reichenberger: Estudios sobre Calderón y el teatro de la Edad de Oro, ed. F. Mundi Pedret y rec. A. Porqueras Mayo y J. C. de Torres, Barcelona, PPU, 1989, pp. 133-152.

- «Desde La púrpura de la rosa», en Las Indias (América) en la literatura del Siglo de Oro. Actas del Congreso Internacional, ed. I. Arellano, Kassel, Reichenberger, 1992, pp. 73-89. 
Chapman, W. G., «Las comedias mitológicas de Calderón», Revista de Literatura, 9/10, 1954, pp. 35-67.

Cotarelo Mori, E., Colección de entremeses, loas, bailes, jácaras y mojigangas desde fines del siglo XVI a mediados del XVIII, Madrid, Bailly-Baillière (NBAE), 1911. Ed. facsímil con estudio preliminar e índices por J. L. Suárez y A. Madroñal, Granada, Universidad de Granada, 2000.

De los Reyes, M., «Relaciones teatrales españolas y austríacas durante el reinado de Leopoldo I y Margarita de Austria (1663-1673)», en Barroco español y austríaco: Fiesta y Teatro en la Corte. Catálogo de la Exposición del mismo título celebrada en el Museo Municipal de Madrid en abril-junio 1994, ed. J. M. Díez Borque y K. F. Rudolf, Madrid, Museo Municipal, 1994, pp. 56-75.

Farré, J., Dramaturgia y espectáculo del elogio. Loas completas de Agustín de Salazar y Torres, Kassel, Reichenberger, 2000.

- "La locura fingida de los actores como "defensa" de su tejné. El caso de algunas loas de presentación de compañía», en Locos, figurones y quijotes en el teatro del los Siglos de Oro. Actas selectas del XII Congreso de la Asociación Internacional de Teatro Español y Novohispano de los Siglos de Oro, ed. G.Vega García Luengos y R. González Cañal, Almagro, Universidad de CastillaLa Mancha, 2007, pp. 125-137.

Flecniakoska, J.-L., La loa, Madrid, SGEL, 1975.

Huerta Calvo, J., «Entremés» en Diccionario de la comedia del Siglo de Oro, ed. F. P. Casa, L. García Lorenzo y G. Vega García Luengos, Madrid, Castalia, 2002.

Lobato, M. L., «Calderón, cisne del Manzanares. Loas cortesanas y conciencia artística», Bulletin of Hispanic Studies, 77, 2000, pp. 229-262.

Mckendrick, M., «El teatro de la corte», en El teatro en España (1490-1700), Palma de Mallorca, Olañeta, 1994, pp. 240-243.

Neumeister, S., «Los retratos de los Reyes en la última comedia de Calderón (Hado y divisa de Leónido y Marfisa, Loa)", en Hacia Calderón. Cuarto coloquio anglogermano (Wolfenbütel, 1975), ed. H. Flasche, K.-H. Körner y H. Mattauch, Berlin, Walter de Gruyter, 1979, pp. 83-91.

Rico, F., «Para el itinerario de un género menor: algunas loas de la Quinta Parte de Comedias», en Homenaje a W. L. Fichter. Estudios sobre el teatro anti guo hispánico y otros ensayos, Madrid, Castalia, 1979, pp. 611-621.

Rodríguez Cuadros, E., La técnica del actor español en el Barroco. Hipótesis y documentos, Madrid, Castalia, 1998.

- y A. Tordera, Calderón y la obra dramática corta, London, Tamesis, 1983.

Ruano de la Haza, J. M., La puesta en escena en los teatros comerciales del Siglo de Oro, Madrid, Castalia, 2000.

Rull, E., "Apuntes para un estudio sobre la función teológica-política de la "loa" en el Siglo de Oro", en Apuntes sobre la loa sacramental y cortesana. 
Loas completas de Bances Candamo, ed. I. Arellano, K. Spang y M. Carmen Pinillos, Kassel, Reichenberger, 1994, pp. 25-36.

SAGE, J., «Calderón y la música teatral», Bulletin Hispanique, 68, 1956, pp. 275 300.

Schizzano Mandel, A., «La presencia de Calderón en la loa de Los tres mayores prodigios», en Hacia Calderón. Octavo Coloquio Anglogermano. Bochum, ed. H. Flasche, Stuttgart, Steiner, 1988, pp. 227-235.

Spang, K., "Aproximación a la loa sacramental y palaciega: notas estructurales», en Apuntes sobre la loa sacramental y cortesana. Loas completas de Bances Candamo, ed. I. Arellano, K. Spang y M. Carmen Pinillos, Kassel, Reichenberger, 1994, pp. 7-24.

VArey, J. E., "Andrómeda y Perseo, comedia y loa de Calderón: afirmaciones artísticoliterarias y políticas», Revista de Musicología, 10, 2, 1987, pp. 529545.

ZAPATA, T., «El teatro y las fiestas públicas en la corte durante el reinado de Carlos II", en Teatro y vida teatral en el Siglo de Oro a través de las fuentes documentales, ed. L. García Lorenzo y J. E. Varey, London, Tamesis, 1991, pp. 156-178.

Zugasti, M., "Aspectos sobre la loa y la música en el umbral de la fiesta barroca», en En torno al teatro del Siglo de Oro, ed. H. Castellón, A. de la Granja y A. Serrano, Almería, Instituto de Estudios Almerienses, 1995, pp. 167-179.

- «Loa», en Diccionario de la comedia del Siglo de Oro, ed. F. P. Casa, L. García Lorenzo y G. Vega García Luengos, Madrid, Castalia, 2002. 
